\title{
Part III Gastrin-like activity in stomachs of patients with peptic ulceration and gastric carcinoma
}

Little has been published on quantitative studies of gastrin-like activity in the human gastrointestinal tract in disease. Uvnäs (1945) and Ferguson (1950) worked on mucosal extracts from operative specimens of stomachs from patients with peptic ulceration and gastric carcinoma. Both authors studied histamine-free extracts and assayed them in anaesthetized cats. Uvnäs reported considerable activity in the antral mucosa in eight out of nine cases of peptic ulcer, and one of the cases two of gastric carcinoma. Ferguson confirmed these findings and noted in addition that the unit activity of the mucosa in cases with inactive duodenal ulcer, gastric ulcer, gastric carcinoma, and in normals are similar, but that the 'active' duodenal ulcers had four times as much gastrin activity. These results can only be taken as roughly quantitative, since the wellknown variation of responses between animals during the assay has not been overcome.

Harper, Blair, and Reed (1962) independently approached the same problem using their own extraction procedure which has been shown to be reproducible, and employing a new method of bioassay with a reference standard and statistical control. Their results agreed in general with those of Ferguson (1950): the concentration of gastrin activity in the antral mucosal extracts from cases of gastric ulcer was about the same as that from normal controls but only about half of that from cases of duodenal ulcer. Extremely low unit activity was found in one case of gastric carcinoma and one of intestinal metaplasia of the antral mucosa.

\section{MATERIALS}

Partial gastrectomy specimens (Billroth I or Polya operation) from 34 patients were studied, comprising 27 with chronic duodenal ulcers, three with benign chronic gastric ulcers, and four with gastric carcinomata. All patients had the following tests done before operation: The basal secretion-acid output was measured during a one-hour period at 'basal' states. Two or more values were obtained from each patient and the mean taken. The 'maximal histamine output' (Card, Marks, and Sircus, 1955) was estimated by giving histamine phosphate, $0.04 \mathrm{mg} . / \mathrm{kg}$. body weight, subcutaneously under antihistamine cover, and the total acid output during the ensuing hour was determined by titration to Töpfer's reagent.

In addition, 22 of the patients with duodenal ulcer had an 'insulin secretion test' done, the total acid output during a two-hour period following an intravenous dose of soluble insulin $(0 \cdot 1$ unit $/ \mathrm{kg}$. body weight) being taken as the response.

In all the above tests, continuous aspiration of gastric juice was practised. All tests were done at least four days before operation.

DUODENAL ULCER CASES This group of patients was selected in the sense that they all had definite indications for surgery, mostly because of complicating stenosis, and the remainder because of persistent dyspepsia or high acid secretion. They have been separated into groups as follows:- Uncomplicated cases (seven patients); cases with severe stenosis, evidenced by a fasting aspirate of $100 \mathrm{ml}$. or more, radiological evidence of gross dilatation of the stomach, and/or confirmation of dilatation of the body of the stomach at operation (five patients); cases with severe stenosis and dilated antrum as well as the body of the stomach (two patients); cases with mild to moderate stenosis, not included in the above (10 patients); cases with combined gastric and duodenal ulcers (three patients). All of the gastric ulcers were well-healed scars in the antrum.

The reason for this classification will become apparent later. It may be added that the methods available at present for assessing the degree of stenosis to the gastric outlet are at best crude and approximate.

GASTRIC ULCER CASES Two of these required surgery because of recurrence after medical treatment, and the third was operated on for massive haemorrhage from the ulcer.

GASTRIC CARCINOMA CASES All were adenocarcinomata. Three were prepyloric lesions (two ulcerative and the third proliferative), and the remaining one was in the body of the stomach on the greater curvature.

\section{METHODS}

All specimens of stomach were obtained within 30 minutes of their resection, opened at the lesser curvature, washed clean of mucus, and divided at the border between the antrum and the body. This border could roughly be judged by the naked eye with some accuracy. Occasional strips of mucosa at the supposed border were studied histologically and all found to be within $0.5 \mathrm{~cm}$. of the true border.

EXTRACTION PROCEDURE Both antral and body mucosa were stripped, weighed, and extracted separately by the method of Grossman, Tracy, and Gregory (1961). The final volume of extract from each portion was 10-12 ml. Preliminary work where the antral mucosa from several hog stomachs were pooled, divided again into portions 
of equal weight, and extracted separately by the same procedure had shown that the extraction procedure gave quantitatively reproducible results.

BIOLOGICAL ASSAY OF GASTRIN-LIKE ACTIVITY The gastrinlike activity of all extracts was assayed by a method reported elsewhere (Lai, 1962, 1963) and in Part I.

Each extract was assayed, and the total gastrin-like activity calculated for the whole antrum. Unit activity per gram of mucosa was also calculated. The histamine contents of all extracts was estimated by the superfused guinea-pig ileum preparation (Adam, Hardwick, and Spencer, 1957) and found to be less than $50 \mathrm{ng} . / \mathrm{ml}$. of the extract. Not more than $1 \mathrm{ml}$. of extract was used in each dose during the assay for gastrin-like activity.

\section{RESULTS}

The results are summarized according to their groups (Tables I and II). In general, the contents of gastrinlike activity in uncomplicated duodenal ulcers are smaller than those with stenosis, and benign gastric ulcers and carcinomata all possess considerable activity similar to or even greater than the average uncomplicated duodenal ulcer. The 'maximal histamine outputs' of patients with severe stenosis were higher than those of the rest (Fig. 1). This last finding is in accordance with the results of Hunt and Kay's (1954) analysis using Ihre's (1938) data, and presumably indicate an increased parietal cell mass in the cases with severe stenosis. Both of the cases with dilated antra had very low total gastrinlike activity. The cases with combined duodenal and gastric ulcers, however, yielded more activity than the average uncomplicated duodenal ulcer.

No definite correlation exists between the total activity and maximal histamine output in any of the above groups. The same applies to the 'basal secretion' plotted against the total gastrin-like activity.

When total gastrin-like activity was plotted against the 'insulin-stimulated acid secretion' (Fig. 2), the uncomplicated duodenal ulcers fell in line with a correlation coefficient of 0.73 . Also, the acid outputs of cases with severe stenosis were distinctly above the less marked ones. This could perhaps be explained by their larger parietal cell

\section{TABLE I}

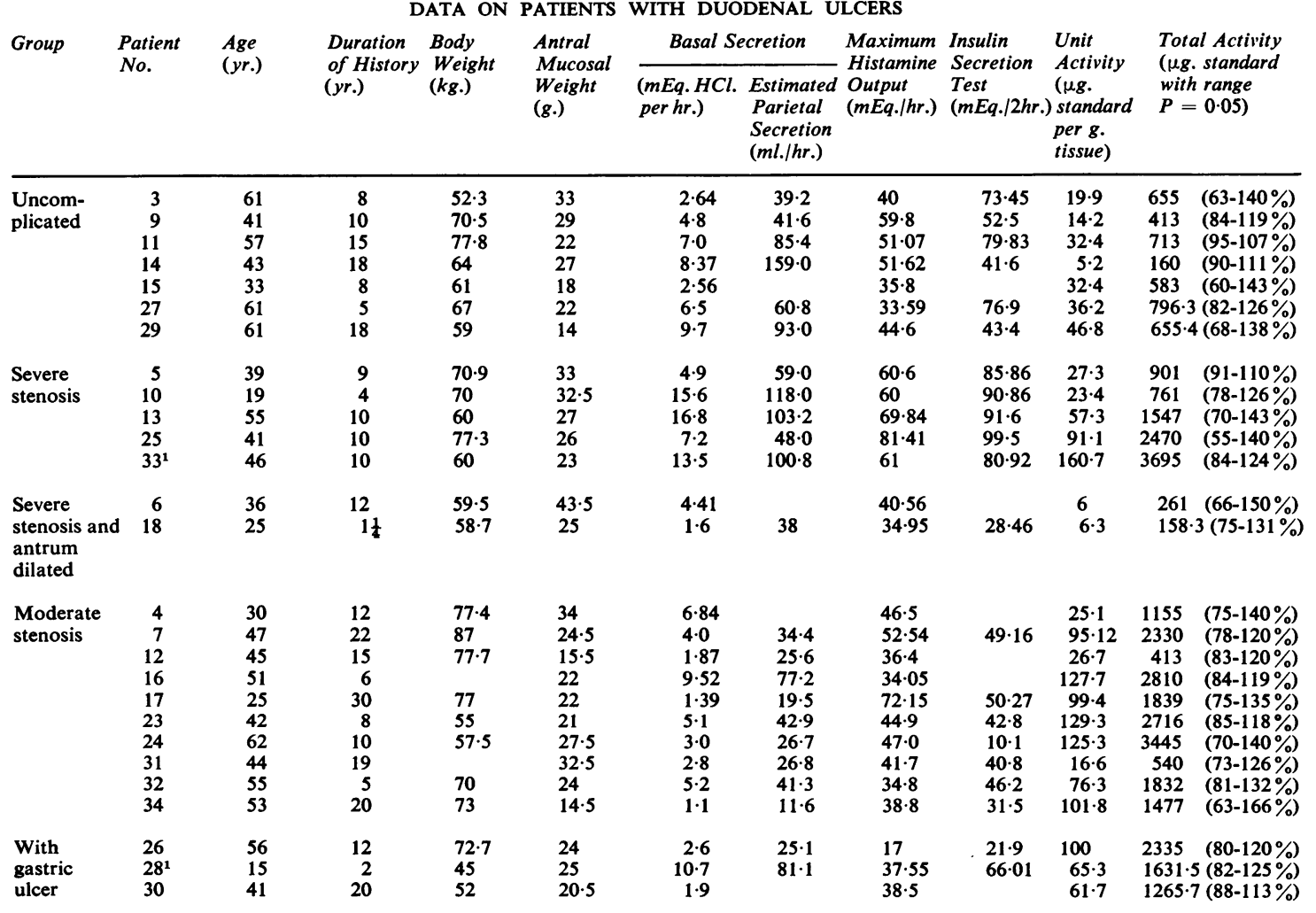

${ }^{1}$ Females. 
TABLE II

DATA FROM PATIENTS WITH BENIGN GASTRIC ULCER AND GASTRIC CARCINOMA

\begin{tabular}{|c|c|c|c|c|c|c|c|c|c|c|c|}
\hline Diagnosis & Case No. & $\operatorname{Age}(y r)$. & $\begin{array}{l}\text { Duration } \\
\text { of History } \\
\text { (yr.) }\end{array}$ & $\begin{array}{l}\text { Body } \\
\text { Weight } \\
\text { (kg.) }\end{array}$ & $\begin{array}{l}\text { Weight of } \\
\text { Antral } \\
\text { Mucosa } \\
\text { (g.) }\end{array}$ & $\begin{array}{l}\text { Basal } \\
\text { Secretion } \\
\text { (mEq./hr.) }\end{array}$ & $\begin{array}{l}\text { Maximal } \\
\text { Histamine } \\
\text { Output } \\
\text { (mEq./hr.) }\end{array}$ & $\begin{array}{l}\text { Unit } \\
\text { Activity } \\
\text { ( } \mu g . \\
\text { standard } \\
\text { per g. } \\
\text { tissue) }\end{array}$ & $\begin{array}{l}\text { Total } \\
\text { ( } \mu g . \\
\text { fiduci } \\
P=\end{array}$ & $\begin{array}{l}\text { Activity } \\
\text { tandard with } \\
\text { al range } \\
.05)\end{array}$ & Remarks \\
\hline $\begin{array}{l}\text { Benign } \\
\text { gastric } \\
\text { ulcer }\end{array}$ & $\begin{array}{l}20^{1} \\
21 \\
22\end{array}$ & $\begin{array}{l}52 \\
53 \\
67\end{array}$ & $\begin{array}{r}8 \\
11 \\
10\end{array}$ & $\begin{array}{l}64 \\
45 \\
60\end{array}$ & $\begin{array}{l}29 \\
22 \cdot 5 \\
22\end{array}$ & $\begin{array}{l}3.5 \\
0.8 \\
1.0\end{array}$ & $\begin{array}{l}13 \\
8 \cdot 25 \\
14\end{array}$ & $\begin{array}{l}87 \cdot 3 \\
28 \cdot 6 \\
50 \cdot 9\end{array}$ & $\begin{array}{r}2533 \\
643 \\
1120\end{array}$ & $\begin{array}{l}(81-134 \%) \\
(74-127 \%) \\
(71-145 \%)\end{array}$ & \\
\hline $\begin{array}{l}\text { Gastric } \\
\text { carcinoma }\end{array}$ & $\begin{array}{l}1 \\
2 \\
8\end{array}$ & $\begin{array}{l}56 \\
39 \\
47\end{array}$ & $\begin{array}{l}3 \\
6 \\
?\end{array}$ & $\begin{array}{l}50 \\
39 \cdot 3 \\
60\end{array}$ & $\begin{array}{l}30 \\
18 \\
41 \cdot 5\end{array}$ & $\begin{array}{l}0.5 \\
4.0 \\
0\end{array}$ & $\begin{array}{r}5 \\
14 \\
0\end{array}$ & $\begin{array}{l}21 \cdot 6 \\
14 \cdot 2 \\
25 \cdot 7\end{array}$ & $\begin{array}{r}650 \\
255 \\
1066\end{array}$ & $\begin{array}{l}(70-135 \%) \\
(75-127 \%) \\
(84-119 \%)\end{array}$ & $\begin{array}{l}\text { Pre-pyloric ulcer } \\
\text { Pre-pyloric ulcer } \\
\text { Presented with } \\
\text { spastic diplegia } \\
\text { for } 7 \mathrm{mth} \text {. Large } \\
\text { pre-pyloric ulcer, } \\
\text { ulcer in middle of } \\
\text { body of stomach }\end{array}$ \\
\hline
\end{tabular}

mass, as suggested above. In order to correct for that and estimate the response of unit number of parietal cells to insulin hypoglycaemia, the insulinstimulated acid secretion in each case was divided by the 'maximal histamine output', and the ratio plotted against the total gastrin-like activity. The results as shown in Fig. 3 show that the correlation with the uncomplicated duodenal ulcers was improved $(r=0.83, P<0.05)$, and that the stenosis cases now fell into the same zone, and though the correlation was not significant, the trend appeared distinct from the uncomplicated cases.

There was no correlation between total gastrinlike activity or unit activity on the one hand, and age and body weight of the patient, duration of history, or size of antrum on the other.

All body mucosal extracts were inactive.

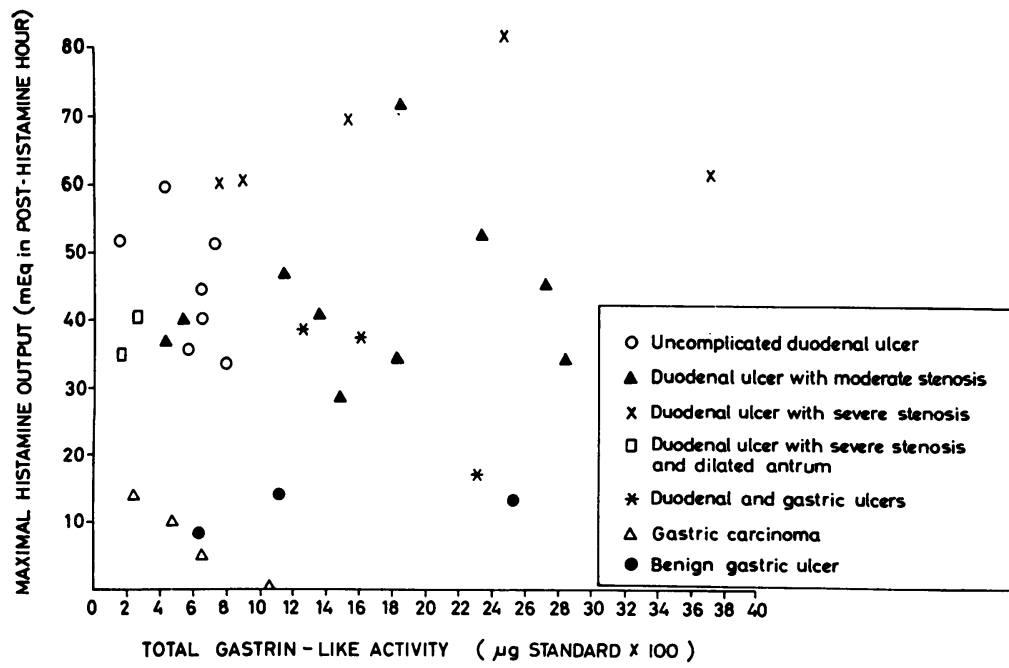

FIG. 1. Total gastrin-like activity plotted against maximal histamine output. 


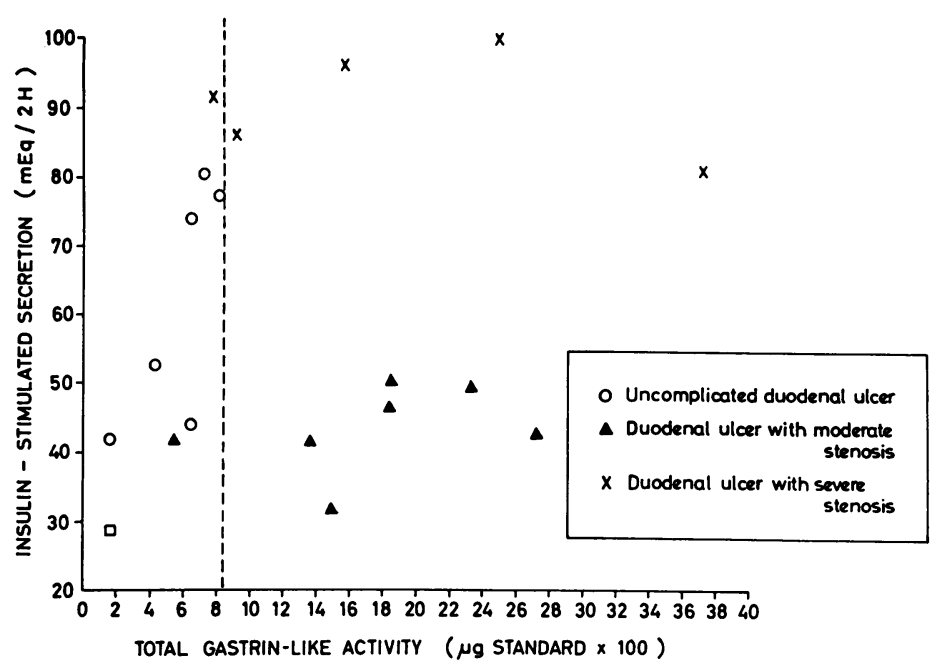

FIG. 2. Total gastrin-like activity plotted against insulin-stimulated acid secretion. The uncomplicated cases can largely be separated from cases with stenosis by the dotted line.

IST / MHT VS. TOTAL GASTRIN - LIKE ACTIVITY

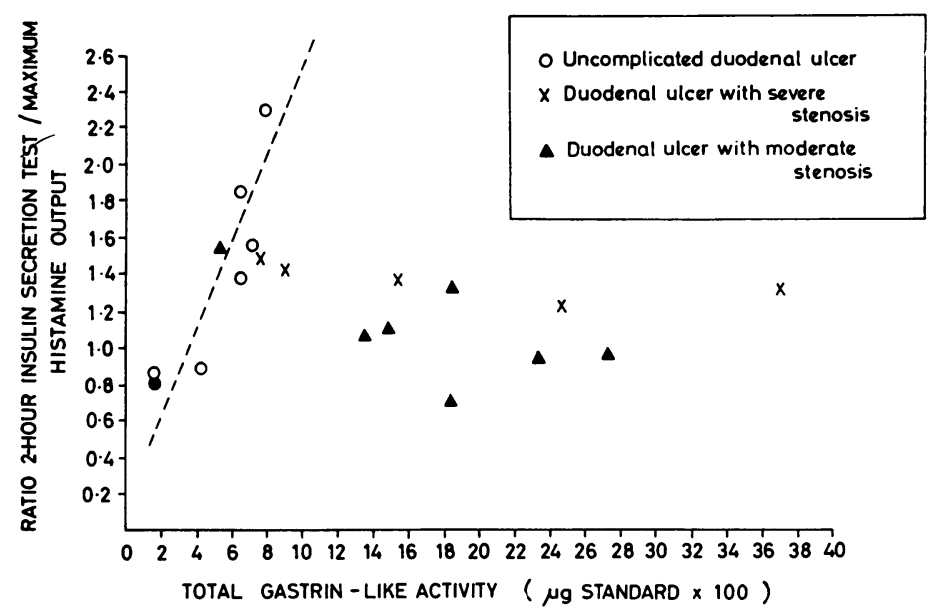

FIG. 3. Total gastrin-like activity plotted against the ratio insulin-stimulated acid secretion/maximal histamine output. Dotted line $=$ calculated regression line for uncomplicated cases. $r=0.83 \quad P<0.05$

assumes that, under strong and possibly maximal vagal stimulation by insulin-induced hypoglycaemia, direct stimulation of the parietal cell is responsible for a constant proportion of the acid output, then the remainder of the acid secretory response to insulin would be accounted for by the amount of gastrin liberated. In this context, the positive correlation between the insulin-stimulated acid secretion and the total gastrin-like activity in the uncomplicated duodenal ulcers in this series is compatible with the assumption that the amount of gastrin liberated into the circulation is proportional to the total gastrin-like activity extractable from the stomach. This is assumed to be true also for duodenal ulcers with stenosis.
Hunt and Kay (1954) have suggested that the increase in parietal cell mass in duodenal ulcer with stenosis was a result of repeated distension of the stomach with consequent stimulation of the parietal cells. The data presented in Fig. 1 are compatible with this view. The cases with stenosis had more gastrin in the antral mucosa (and hence probably in the circulation) than the uncomplicated cases.

The results in Fig. 3 indicate that the insulinstimulated secretion per secretory unit, represented by the ratio 'insulin-secretion test/maximal histamine output', remained about the same, despite increase in the total gastrin-like activity beyond a point at about the equivalent of $800 \mu \mathrm{g}$. of the standard. 
This might represent a plateau response to maximal levels of circulating gastrin. There was no definite evidence of inhibition of responses during the pre-operative 'insulin secretion tests' in patients with high total gastrin-like activity in their antra, as was observed in dogs with Heidenhain pouches responding to large doses of injected gastrin extracts (Gillespie and Grossman, 1963).

The possible role of gastrin in the aetiology of duodenal ulceration has been suggested by Gillespie and Kay (1961) who showed that antrectomy alone led to healing of the duodenal ulcer in four patients. The Zollinger-Ellison syndrome provides an extreme example of possible effects of excessive gastrin (or gastrin-like substance) in circulation. The idea of gastrin possibly playing a role as a trophic hormone to the parietal cells has been summarized by Card (1963), who cited in support a case of ZollingerEllison syndrome when 'maximal histamine output' of the patient progressively fell after partial resection of the pancreas and left adrenalectomy without any surgery on the stomach. The failure to demonstrate a correlation between the 'maximal histamine output' and gastrin-like activity in this present study dose not support this idea but certainly does not exclude it, since apart from all the unknown factors mentioned above, this series could well have included cases with a large parietal cell mass to start with, irrespective of the gastrin content in the antrum.

\section{SUMMARY}

The gastrin-like activity in the antral mucosa of patients with duodenal ulcer, gastric ulcer, and gastric carcinoma were estimated by bioassay employing a rat preparation, and attempts were made to correlate the findings with the pre-operative gastric acid secretory studies.
I am deeply grateful to Professor W. L. M. Perry and to Dr. H. M. Adam of the Department of Pharmacology, University of Edinburgh Medical School, and to Dr. W. I. Card of the Gastrointestinal Unit, Western General Hospital, Edinburgh, for their guidance, helpful criticism, and encouragement throughout this work.

Grants from the Medical Research Council to cover the cost of equipment and current laboratory expenses, and a personal grant to the author during the latter part of this work are gratefully acknowledged.

\section{REFERENCES}

Adam, H. M., Hardwick, D. C., and Spencer, K. E. V. (1957). A method of estimating histamine in plasma. Brit. J. Pharmacol., 12, 397-405.

Card, W. I. (1963). Surgical physiology of the gastrointestinal tract, Symp. roy. Coll. Surg. Edinb., p. 81.

-, Marks, I. N., and Sircus, W. (1955). Observations on achlorhydria. J. Physiol. (Lond.), 130, 18P.

Ferguson, D. J. (1950) Studies on gastrin from human stomachs. Surg. Forum, 1, 84-88.

Gillespie, I. E., and Kay, A. W. (1961). Effect of medical and surgical vagatomy on the augmented histamine test in man. Brit. med. J. 1, 1557-1560.

- , and Grossman, M. I. (1963). Inhibition of gastric secretion by extracts containing gastrin. Gastroenterology, 44, 301-310.

Grossman, M. I., Tracy, H. J., and Gregory, R. A. (1961). ZollingerEllison syndrome in a Bantu woman, with isolation of a gastrinlike substance from the primary and secondary tumors. II. Extraction of gastrin-like activity from tumors. Gastroenterology, 41, 87-91.

Harper, A. A., Blair, E. L., and Reed, J. D. (1962). Proc. int. Union physiol. Sci. 22nd international Congress, Leyden. vol. 1, p. 334-337.

Hunt, J. N., and Kay, A. W. (1954). The nature of gastric hypersecretion of acid in patients with duodenal ulcer. Brit. med. J., 2, 1444-1446.

Ihre, B. (1938). Human gastric secretion. Acta med. scand., supp. 95.

Lai, K. S. (1962). A method of biological assay of gastrin and its application to the study of human tissues. Ph. D. Thesis, University of Edinburgh.

- (1963). Surgical physiology of the gastrointestinal tract. Symp. roy. Coll. Surg. Edinb., p. 85.

Uvnäs. B. (1945). Presence of gastric secretory excitant in human gastric and duodenal mucosa. Acta physiol. scand., 10, 97. 